\title{
Effectiveness Of Anger Management Therapy On Anger Behaviour Among Alcohol Dependents
}

*Mrs.Prabavathy $S \&{ }^{* *}$ Mr.Dhivagar $S$

\section{Abstract:}

Aim: This Study aims to assess the effectiveness of Anger Management Therapy on anger behaviour among alcohol dependents in Bharatha MathaDeaddiction Centre, Puducherry. Materials and Methods: Quasi-experimental research design with pre-test and post-test was adopted. Thirty samples residing at Bharatha MathaDeaddiction Centre, Ariyankuppam, Puducherry were selected by using Purposive sampling technique. The data were collected through interview method and pre-test data collection was done by using anger behaviour response questionnaire. 30 samples were divided into five groups (6 in each group) and Anger Management Therapy was administered for the duration of 15-20 minutes daily for 7 days and the post-test was conducted. The data were analyzed in terms of using paired' $t$ ' test and Mann - whitney test. Result: The study showed that the pre-test mean score was 37.2 and standard deviation is 11.2 and in the post-test mean score was 43.8 and standard deviation was 9.7736. And p-value was 0.02 and this study reveals that Anger Management Therapy is statistically significant in reduction of anger behavior among alcohol dependents

Keywords: Anger behaviour, Anger Management Therapy, Alcohol dependents

\section{INTRODUCTION}

Alcohol is an illness characterized by significant impairment that is directly associated with persistent and excessive use of alcohol. ${ }^{1}$ It is a chronic and progressive disease featured by loss of control over the use of alcohol with subsequent social, legal, psychological, and physical consequences. It is a complex disease, which has been misunderstood and stigmatized. ${ }^{2}$

According to TIMES OFINDIA (2012) reports a global study has found out that alcohol consumption in India has been
Raised by $55 \%$ over a period of 20 years, an alcoholic dependent is a major health problem in India. ${ }^{3}$ an estimated 32 to $45 \%$ of adult Indian population reports high usage of alcohol I their lifetime. 5 to $7 \%$ is abuser of alcohol and 10 and20 million persons have been estimated to be in need of treatment for alcohol dependence. the reports also indicated that there is a steady rise in per capita alcohol consumption every year. ${ }^{4}$

Anger behaviour is a type of human emotional behaviour. It can cause physical or emotional harm to others. it may ranger verbal abuse to physical abuse. 
The harm associate with the consumption of alcohol, particularly among young people. ${ }^{5}$

Violence causes more than 1.6 million deaths world-wide every year. violence is one of the leading causes of death in all parts of the world for persons. for this situation, they need to recover from this problem and manage their anger. anger management therapy is one of the effective intervention to help a person decrease the heightened emotional and physiological arousal often associated with anger. ${ }^{5}$

\section{Objectives}

- To assess the level of anger behaviour among alcohol dependents.

- To evaluate the effectiveness of anger management therapy on anger behaviour among alcohol dependents.

- To associate the level of anger behaviour among alcohol dependents with the selected demographic variables.

\section{Hypotheses}

$\mathbf{H}_{1}$ : There is a difference in the reduction of anger behaviour before and after anger management therapy among alcohol dependents.
$\mathbf{H}_{2}$ : There is a significant association between the levels of anger behaviour among the alcohol dependents and the selected demographic variables.

\section{Methodology}

Quasi-experimental research design one group pre-test and post-test was adopted. Thirty alcohol dependents residing at Bharatha MathaDeaddiction Centre, Ariyankuppam, Puducherry were selected by using Purposive sampling technique. The data were collected through interview method and pre-test data collection was done by using anger behaviour response questionnaire. 30 samples were divided into five groups (6 in each group) and Anger Management Therapy was administered for the duration of 15-20 minutes daily for 7 days and the post-test was conducted. The data were analyzed in terms of both descriptive and inferential statistics by using paired' $t$ ' test and Kruskal- wallis/ Mann whitney test.

\section{Results}

Table I Showed that the level of anger behaviour among alcohol dependents in pretest level of anger behaviour among subjects. Out of 30 subjects, mean score of 19.40 had adaptive response and the p-value was 0.5901

Table-I: Assess the level of anger behavior among alcohol dependents.

\begin{tabular}{|c|c|c|}
\hline Adaptive Response & Pre-Test & Post-Test \\
\hline Mean & 19.4000 & 20.1667 \\
\hline Standard Deviation & 6.1734 & 4.2676 \\
\hline t Stat & \multicolumn{3}{|c|}{0.5447} \\
\hline p-value & \multicolumn{3}{|c|}{0.5901} \\
\hline
\end{tabular}


Table-II: Effectiveness of anger management therapy on level of anger behavior among alcohol dependents.

\begin{tabular}{|c|c|c|}
\hline OVERALL & PRE-TEST & POST-TEST \\
\hline Mean & 37.2667 & 43.8333 \\
\hline Standard Deviation & 11.2063 & 9.7736 \\
\hline t Stat & \multicolumn{2}{|c|}{-2.4216} \\
\hline$p$-value & \multicolumn{2}{|c|}{0.0219} \\
\hline
\end{tabular}

Table II showed that the mean, standard deviation, paired ' $\mathrm{t}$ ' value of subjects with the level of anger behaviour during pre-test and post-test. It shows that the post-test mean value anger behaviour score of 43.833 was lower than the pre-test score 37.2667 and the standard deviation level in the post-test was 9.7736 and in the pre-test was 11.2063. The obtained' value of -2.4216 was highly statistically significant $(0.000)$ at $\mathrm{p}<0.001$ level. This data concludes that there was significant difference between mean scores of pre-test and post-test level of anger behaviour.

It was inferred that anger management therapy was highly effective in reduction of anger behaviour among alcohol dependents. Hence the stated research hypothesis $\left(\mathrm{H}_{1}\right)$ was accepted. It was showed that anger management therapy was significantly in reduction of anger behaviour among alcohol dependents.

To associate the level of anger behaviour among alcohol dependents with the selected demographic variables.

The data reveals that there was significant association between the type of personality and the level of anger behaviour at $0.0017(\mathrm{p}<0.005)$. Hence the research hypothesis $\left(\mathrm{H}_{2}\right)$ was accepted. Thus the conclusion is that the types of personality had influence on level of anger behaviour among alcohol dependents.

\section{Conclusion}

The main study was to assess the effectiveness of anger management therapy on anger behaviour among alcohol dependents in Bharatha MathaDeaddiction Centre, Puducherry.

This study revealed that the level of anger behaviour was high among alcohol dependents residing in de addiction centre. And the post-test mean level of anger score was lower than the pre-test score after administration of anger management therapy. This study proves that anger management therapy was effective in reduction of anger among alcohol dependents. Hence, the anger management therapy is an effective intervention that can be given to alcoholic dependents on regular basis in order to reduce their anger and their caregivers can also practice it whenever possible.

\section{References:}

1. Stuart W Gail "Principles and Practices of Psychiatric Nursing", 19th edition Mosby' Elsevier publications. 2008

2. Yas JN Ahuja N. "Textbook of post graduate psychiatry", Jaypee brothers. $2^{\text {nd }}$ edition. 2007. page no. 187-91

3. DERB's ElakkuvanaBhaskara raj, 'Textbook of Nursing Research and Statistics EMMESS medical publishers 2014.

4. Monica, "Early alcohol use and problem drinking among students in Zambia and uganda`. 2011 
5. AnnamitraBarik, "Alcohol use-related problems among a rural Indian population of west bengal, 2015. page no: $215-23$

6. Joel M. Francis, "The epidemiology of alcohol use and alcohol disorders among young people in northen Tanzania", 2015.

7. Kaplan and sadock, "comprehensive textbook of psychiatry", $7^{\text {th }}$ edition philadelphia: lippincott publication, page no: 2980-3084.

8. Journal of Human Kinetics, Georges Steffgen, "Anger Management-evaluation of a anger management therapy for tennis player", 2017. page no: 65-73

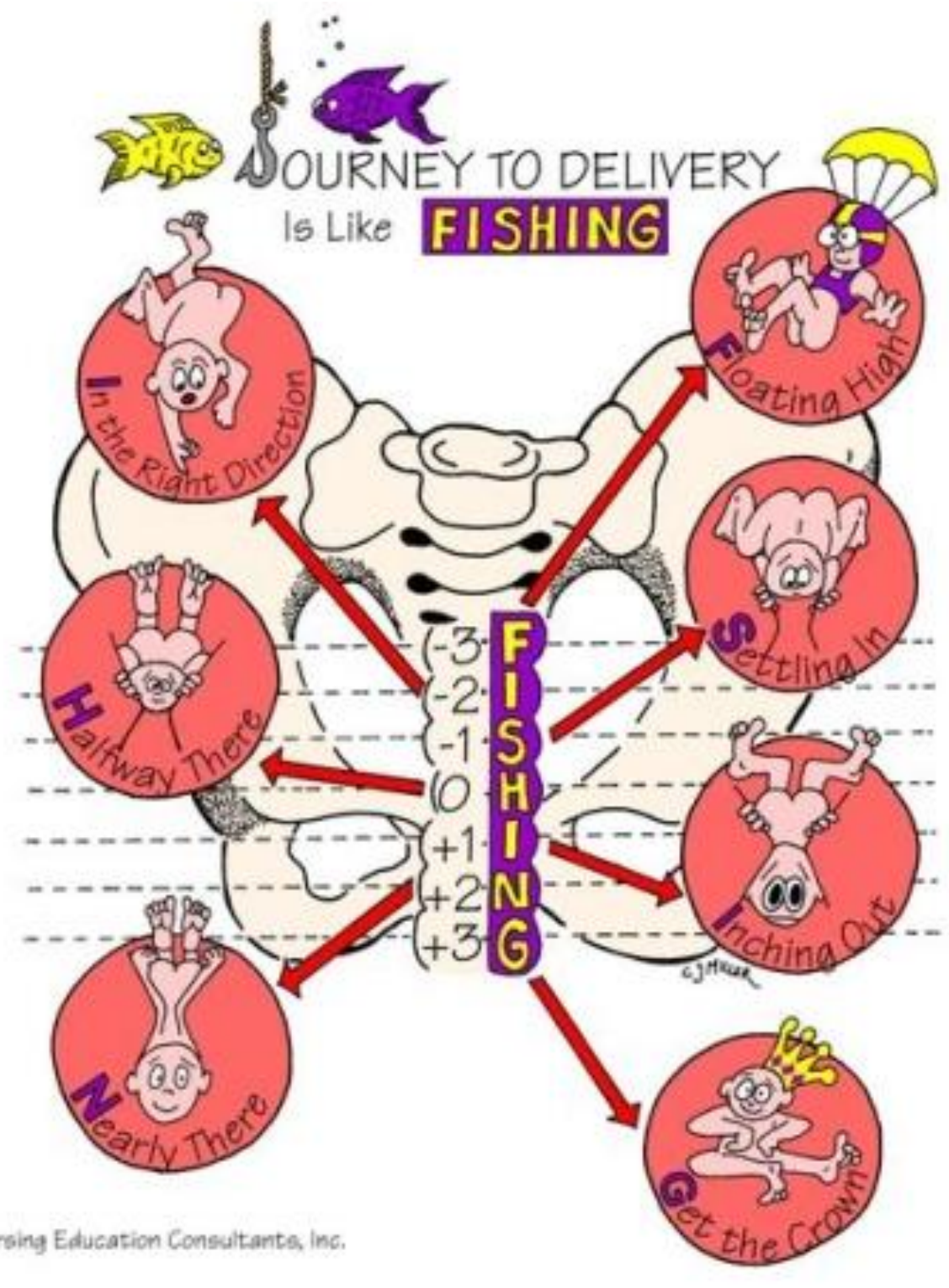

